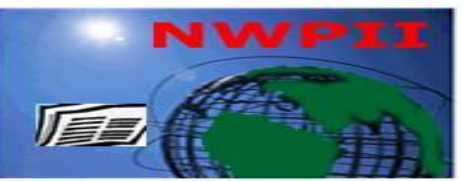

American Journal of Biomedical Sciences

ISSN: 1937-9080

nwpii.com/ajbms

\title{
Detection of catechol-O-methyltransferase (COMT) Val158Met Polymorphism by a New Optimized PCR-RFLP Method
}

\author{
Bassam Lajin $^{1 *}$, Amal Alachkar ${ }^{2}$ \\ ${ }^{1}$ Department of Analytical Chemistry, Faculty of Pharmacy, University of Aleppo, Aleppo, Syria \\ ${ }^{2}$ Department of Pharmacology, Faculty of Pharmacy, University of Aleppo, Aleppo, Syria \\ *Corresponding Author \\ Bassam Lajin \\ Research Associate \\ Faculty of Pharmacy, \\ University of Aleppo, Aleppo, Syria \\ Email: Bassaml7@yahoo.co.uk
}

Received: 15 February 2011; | Revised: 5 March 2011; | Accepted: 19 March 2011

\begin{abstract}
The transition from $\mathrm{G}$ to $\mathrm{A}$ at nucleotide 21881 of the human catechol-O-methyltransferase (COMT) gene produces a functional genetic polymorphism (Val158Met) that has been shown to render an enzyme with reduced activity. A new highly optimized PCR-RFLP method for the detection of this polymorphism is described. The method utilizes the same restriction enzyme commonly used for PCR-RFLP detection of Val158Met, NlaIII. However, The SNP-containing fragment to be amplified was selected as to extremely simplify the restriction fragments pattern generated resulting in faster separation using $2.5 \%$ agarose gel electrophoresis. The presence of a Valine or Methionine allele is indicated by a $108 \mathrm{bp}$ or $72 \mathrm{bp}$ fragment, respectively. Electrophoresis conditions were optimized to decrease separation time and distance down to 16 min and $3 \mathrm{~cm}$, respectively. The proposed method can serve as a fast, simple, and cost effective alternative to the PCR-RFLP methods commonly used for the detection of Val158Met, a polymorphism that is being thoroughly investigated in a broad range of biomedical fields.
\end{abstract}

Keywords: Catechol-O-methyltransferase (COMT); SNP; NlaIII; Val158Met; RFLP.

\section{Introduction}

Catechol- $O$-methyltransferase (COMT) is a widespread enzyme that catalyzes the transfer of the methyl group of S-adenosyl-l methionine (AdoMet) to the catechol substrate. High COMT activity is found in the liver, kidney, gut wall, and the brain [1,2]. A single COMT gene codes for two separate enzymes, soluble (S-COMT) and membrane bound (MB-COMT) forms. S-COMT consists of 221 amino acids. MB-COMT has an additional amino-terminal extension of 50 amino acids in humans [3-5]. The human gene for COMT is located at the chromosome 22q11 [6]. The level of COMT enzyme activity is genetically polymorphic in human tissues. A common single nucleotide polymorphism (SNP) in the COMT gene that has been extensively typed for association studies is the exon 4 functional variant, a transition from $\mathrm{G}$ to $\mathrm{A}$ that results in the creation 
of an NlaIII site in the DNA and a Valine (at codon 108 of S-COMT and codon 158 of MBCOMT) to Methionine amino acid change in the protein. This change in a single amino acid from Val to Met results in a decrease of $67-75 \%$ in enzymatic activity $[7,8]$, and is referred to by the L (low activity) allele, in contrast to the wild type $\mathrm{H}$ high activity allele. COMT is an obvious candidate gene for a number of neurologic disorders that involve noradrenergic or dopaminergic systems. The case-control association design has been used to study its possible role in a vast number of neurological disorders including Parkinson's disease (PD) [911], obsessive-compulsive disorder (OCD) [12], schizophrenia (SZ) [13-15], unipolar affective disorder (UPD) [16], and bipolar affective disorder (BPD) [17]. Since COMT contributes to the metabolism of catechol estrogens, the effects of Val158Met have also been investigated in breast cancer [18-20]

One of the most commonly used methods for the detection of SNPs is based on the alteration of a restriction enzyme recognition site in the presence of either of two alleles, making the restriction enzyme unable to cleave the DNA. This method is usually Polymerase Chain Reaction based and is known as PCR-RFLP (Polymerase Chain Reaction - Restriction Fragment Length Polymorphism). PCR-RFLP methods are known to be highly specific, extremely robust, costeffective, and easy to apply. However, their most common drawback is high time consumption due to the several steps included.

PCR-RFLP (with NlaIII as the restriction enzyme) has been the most widely used method for the detection of Val158Met [21-25].

The aim of the present work was to introduce a new optimized PCR-RFLP method that can reduce cost and time consumption and increase detection throughput.

\section{Materials and Methods}

\subsection{DNA isolation}

Genomic DNA was isolated from $200 \mu \mathrm{L}$ venous blood using a spin column format kit (EuroGold $^{\mathrm{TM}}$ Blood DNA mini kit, Euroclone,
Italy). The procedure was carried out according to the manufacturer recommendations.

\subsection{PCR amplification of the SNP-containing fragment}

A 108 bp DNA fragment containing the SNP was amplified using the PCR method. The sequence of the reverse primer used was selected as to anneal to and modify the constant recognition sequence of NlaIII found in close proximity to the SNP under study through a mismatch, replacing guanine with thymine as illustrated in the schematic diagram in Fig. 1. The forward primer position was selected to surpass another constant NlaIII recognition sequence (Fig. 1).

The PCR reaction was carried out in a total volume of $20 \mu \mathrm{L}$ containing 100-150 ng genomic DNA as the template, $0.5 \mu \mathrm{M}$ of each primer (synthesized by VBC-Biotech, Austria), $2.3 \mathrm{mM}$ $\mathrm{MgCl} 2,200 \mu \mathrm{M}$ of each dNTP, 1X Taq buffer (10 $\mathrm{mM}$ Tric- $\mathrm{HCl} \mathrm{pH} 8.4,50 \mathrm{mM} \mathrm{KCl}$ ) and 0.75 units of Taq DNA polymerase (Fermentas, Lithuania). PCR amplification was carried out in a MasterCycler ${ }^{\circledR}$ thermal cycler (Eppendorf, Germany) with an initial denaturation step at 94 ${ }^{\circ} \mathrm{C}$ for $5 \mathrm{~min}$ followed by 32 cycles of $94{ }^{\circ} \mathrm{C}$ for 30 sec, $62{ }^{\circ} \mathrm{C}$ for $30 \mathrm{sec}$ and $72{ }^{\circ} \mathrm{C}$ for $10 \mathrm{sec}$, and a final extension step at $72{ }^{\circ} \mathrm{C}$ for $5 \mathrm{~min}$. The sequences for the forward and reverse primers were 5'-CGAGGCTCATCACCATCGAGATC-3' and 5'-CTGACAACGGGTCAGGAATGCA-3', respectively.

\subsection{Restriction Digestion}

The whole volume of the unpurified PCR product was mixed with $1 \mu \mathrm{L}$ of FastDigest ${ }^{\circledR}$ NlaIII enzyme (Fermentas ${ }^{\circledR}$, Lithuania), $2 \mu \mathrm{L}$ of 10X FastDigest ${ }^{\circledR}$ green buffer and $17 \mu \mathrm{L}$ of nuclease free water to make up a total volume of $40 \mu \mathrm{L}$. Digestion was ensured to be complete following incubation at $37{ }^{\circ} \mathrm{C}$ for $15-20 \mathrm{~min}$.

\subsection{Gel Electrophoresis}

Tris-Borate-EDTA (TBE) buffer was used for electrophoresis. TBE was used at a concentration lower than that commonly used (only $0.2 \mathrm{X}$ ) in order to decrease electric conductivity allowing the application of electric field strength as high as $16 \mathrm{~V} / \mathrm{cm}$. This resulted in sharp bands and short 
electrophoresis time and separation distance. Agarose gel was used as the separation medium with a concentration of $2.5 \%$.

Ethidium Bromide was incorporated into the gel with a concentration of $1 \mu \mathrm{g} / \mathrm{mL}$. The gel was illuminated with WiseDoc ${ }^{\circledR}$ gel documentation system (Daihan Scietific, South Korea) and directly photographed using a handheld digital camera.

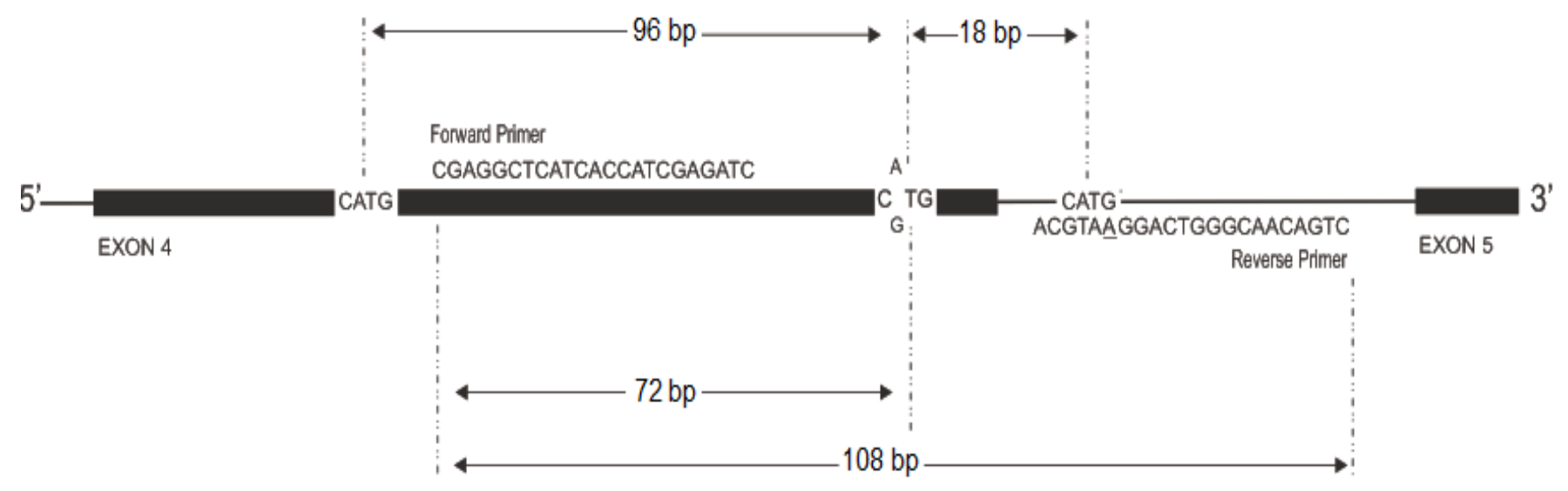

Figure 1 A schematic illustration of the COMT gene showing the location of NlaIII recognition sequences (CATG) relative to primer annealing sites. Fragments are not drawn at scale. The underlined base indicates the introduced mismatch. Exons are shown as black boxes whereas introns are shown as lines. The restriction enzyme will always cleave in the two constant recognition sequences found in close proximity to the polymorphic nucleotide resulting in a $96 \mathrm{bp}$ or $114 \mathrm{bp}$ fragment and indicating the presence of a Met or Val allele, respectively. In the proposed method the close constant recognition sequence is modified by annealing to the reverse primer, and the difference between the indicative bands is thus increased up to $36 \mathrm{bp}$.

\section{Results and Discussion}

Digestion of the amplified fragment with NlaIII showed 3 bands in heterozygotes (108, 72 and $36 \mathrm{bp})$ as expected according to Fig .1. The amplified fragment remained intact in Val homozygotes after digestion, with agarose gel electrophoresis showing a single $108 \mathrm{bp}$ band. In Met homozygotes, 2 bands were produced (72 and 36 bp) (Fig. 2). Separation of the 3 distinctive bands was achieved within 16 min with separation distance not exceeding $3 \mathrm{~cm}$.

The restriction enzyme NlaIII has been used for Val158Met detection by PCR-RFLP [21-25]. However, the presence of NlaIII recognition sequences in close proximity to the SNP locus has limited many aspects of the use of PCR-RFLP in the detection. In particular, the presence of a constant recognition sequence as close as 18 nucleotides to the recognition sequence containing the polymorphic nucleotide means that the absence or presence of the polymorphism is governed by a relatively small difference in the length of fragments generated (18 bp). Polyacrylamide gels have been used to resolve such small differences in fragment length [26]. However, the vertical polyacrylamide gels are relatively difficult to prepare and allow the simultaneous analysis of a relatively small number of samples limited by the inability to insert multiple gel combs. Acrylamide is also known to be toxic [27]. On the contrary, horizontal agarose gels are easier to prepare and stain, non toxic and also allow large number of samples to be loaded on a single gel through the use of multiple adjacent combs. 


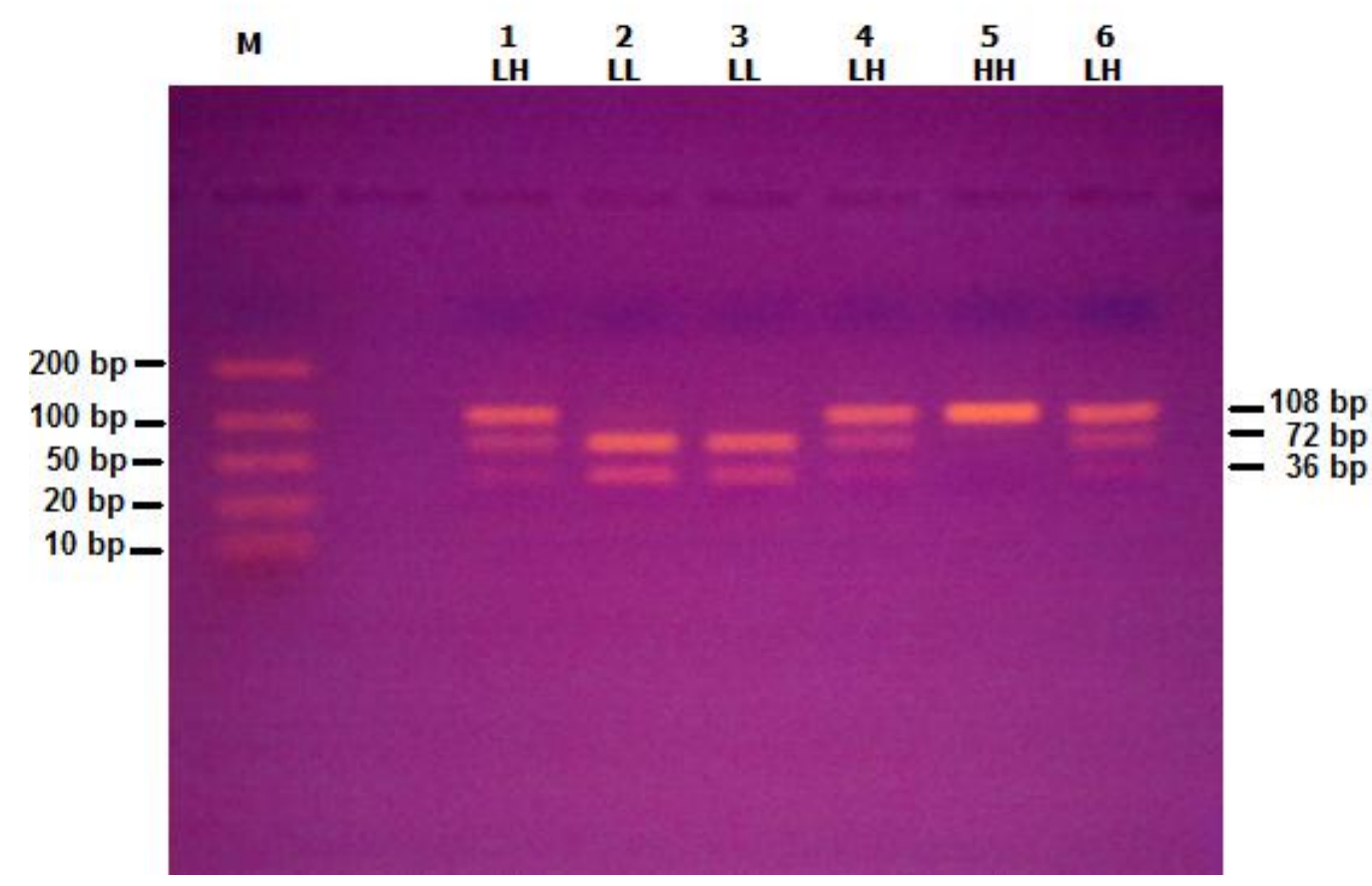

Figure 2 Agarose gel electrophoretogram of Val158Met COMT polymorphism as detected by the proposed PCR-RFLP method. The electrophoretogram shows genotypes for 6 different subjects. A single band (108 bp) indicates a homozygous genotype for the high activity allele $(\mathrm{HH})$. The presence of 2 bands (72 and $36 \mathrm{bp}$ ) is indicative of a homozygous genotype for the low activity allele (LL). Heterozygous genotype (LH) is characterized by the presence of 3 fragments (108, 72 and $36 \mathrm{bp}$ ). M: Molecular weight ladder.

By eliminating the constant recognition sequence found in close proximity to the recognition sequence of interest, which is a novel approach, the ability of medium percentage agarose gels to resolve the informative bands within a short electrophoresis time was significantly increased, as the difference in length between the indicative fragments was increased from $18 \mathrm{bp}$, which is commonly found in the literature [21-25], to $36 \mathrm{bp}$, which is unprecedented. Therefore, the use of high concentration agarose gels (4-5\%) which are costly and difficult to handle and prepare, can be avoided [28,29]. Furthermore, it was possible to reduce electrophoresis buffer concentration used down to $20 \%$ of that commonly used in order to allow the application of a high electric field strength $(16 \mathrm{~V} / \mathrm{cm})$ resulting in extremely short separation time $(16 \mathrm{~min})$ and distance $(3 \mathrm{~cm})$. The separation distance attained was short enough to maximize the number of samples that can be loaded and analysed on a single gel. The bands pattern was extremely simple with 3 bands (108, 72 and $36 \mathrm{bp}$ ), 2 bands (72 and $36 \mathrm{bp}$ ), or 1 band
(108 bp) indicating a Val/Met, Met/Met or Val/Val genotype, respectively. The extreme simplicity of the bands pattern renders the use of DNA ladders or molecular weight markers unnecessary for routine detection, with the ability to determine the genotype based solely on the number of the resulting bands shown following electrophoresis.

\section{Conclusion}

We have developed a highly optimized PCRRFLP method that possesses clear advantages over the PCR-RFLP methods widely used for the detection of Val158Met, including simplicity, high speed, and high detection throughput. The proposed method can serve as an invaluable tool in case-control association studies involving the Val158Met which is commonly investigated in a broad range of biomedical fields. 


\section{References}

[1] Axelrod J." O-methylation of epinephrine and other catechols in vitro and in vivo." (1957). Science 126(3270): 400-401. 10.1126/science. 126.3270 .400

[2] Guldberg, H. C. and C. A. Marsden (1975). "Catechol-O-methyl transferase: pharmacological aspects and physiological role." Pharmacol Rev 27(2): 135-206.

[3] Bertocci, B., V. Miggiano, et al. (1991). "Human catechol-O-methyltransferase: cloning and expression of the membraneassociated form." Proc Natl Acad Sci U S A 88(4): 1416-1420. 10.1073/pnas.88.4.1416

[4] Lundstrom, K., M. Salminen, et al. (1991). "Cloning and characterization of human placental catechol-O-methyltransferase cDNA." DNA Cell Biol 10(3): 181-189.

[5] Mannisto, P. T. and S. Kaakkola (1999). "Catechol-O-methyltransferase (COMT): biochemistry, molecular biology, pharmacology, and clinical efficacy of the new selective COMT inhibitors." Pharmacol Rev 51(4): 593-628.

[6] Grossman, M. H., B. S. Emanuel, et al. (1992). "Chromosomal mapping of the human catechol-O-methyltransferase gene to 22q11.1---q11.2." Genomics 12(4): 822-825. doi:10.1016/0888-7543(92)90316-K

[7] Lotta, T., J. Vidgren, et al. (1995). "Kinetics of human soluble and membrane-bound catechol O-methyltransferase: a revised mechanism and description of the thermolabile variant of the enzyme." Biochemistry 34(13): 4202-4210. DOI: 10.1021/bi00013a008

[8] Lachman, H. M., D. F. Papolos, et al. (1996). "Human catechol-O-methyltransferase pharmacogenetics: description of a functional polymorphism and its potential application to neuropsychiatric disorders." Pharmacogenetics 6(3): 243-250.

[9] Hoda, F., D. Nicholl, et al. (1996). "No Association between Parkinson's Disease and Low-Activity Alleles of CatecholOMethyltransferase." Biochemical and Biophysical Research Communications 228(3): 780-784. doi:10.1006/bbrc.1996.1731
[10] Kunugi, H., S. Nanko, et al. (1997). "High and low activity alleles of catechol-Omethyltransferase gene: ethnic difference and possible association with Parkinson's disease." Neurosci Lett 221(2-3): 202-204. doi:10.1016/S0304-3940(96)13289-4

[11] Syvanen, A. C., C. Tilgmann, et al. (1997). "Genetic polymorphism of catechol-Omethyltransferase (COMT): correlation of genotype with individual variation of $\mathrm{S}$ COMT activity and comparison of the allele frequencies in the normal population and parkinsonian patients in Finland." Pharmacogenetics 7(1): 65-71.

[12] Karayiorgou, M., M. Altemus, et al. (1997). "Genotype determining low catechol-Omethyltransferase activity as a risk factor for obsessive-compulsive disorder." Proc Natl Acad Sci U S A 94(9): 4572-4575. 10.1073/pnas.94.9.4572

[13] Chen, C. H., Y. R. Lee, et al. (1997). "Association study of NlaIII and MspI genetic polymorphisms of catechol-Omethyltransferase gene and susceptibility to schizophrenia." Biol Psychiatry 41(9): 985987.

[14] Daniels, J. K., N. M. Williams, et al. (1996). "No evidence for allelic association between schizophrenia and a polymorphism determining high or low catechol Omethyltransferase activity." Am J Psychiatry 153(2): 268-270.

[15] Okochi, T., M. Ikeda, et al. (2009). "Metaanalysis of association between genetic variants in COMT and schizophrenia: an update." Schizophr Res 110(1-3): 140-148. doi:10.1016/j.schres.2009.02.019

[16] Ohara, K., M. Nagai, et al. (1998). "Low activity allele of catechol-o-methyltransferase gene and Japanese unipolar depression." Neuroreport 9(7): 1305-1308.

[17] Li, T., H. Vallada, et al. (1997). "Catechol-Omethyltransferase Val158Met polymorphism: frequency analysis in Han Chinese subjects and allelic association of the low activity allele with bipolar affective disorder." Pharmacogenetics 7(5): 349-353.

[18] Lavigne, J. A., J. E. Goodman, et al. (2001). "The effects of catechol-O-methyltransferase 
inhibition on estrogen metabolite and oxidative DNA damage levels in estradioltreated MCF-7 cells." Cancer Res 61(20): 7488-7494.

[19] Lin, W. Y., Y. C. Chou, et al. (2005). "Polymorphic catechol-O-methyltransferase gene, duration of estrogen exposure, and breast cancer risk: a nested case-control study in Taiwan." Cancer Detect Prev 29(5): 427-432. doi:10.1016/j.cdp.2005.07.003

[20] Sazci, A., E. Ergul, et al. (2004). "Catechol-Omethyltransferase Val 108/158 Met polymorphism in premenopausal breast cancer patients." Toxicology 204(2-3): 197-202. doi:10.1016/j.tox.2004.06.026

[21] Mynett-Johnson La, Murphy Ve, Claffey E, Shields Dc, Mckeon P. (1998). Preliminary evidence of an association between bipolar disorder in females and the catechol- $O$-methyltransferase gene. Psychiatr Genet 8: 221-225.

[22] Tajouri, L., V. Martin, et al. (2006). Genetic investigation of methylenetetrahydrofolate reductase (MTHFR) and catechol-O-methyl transferase (COMT) in multiple sclerosis. Brain Research Bulletin 69(3): 327-331. doi:10.1016/j.brainresbull.2006.01.005

[23] Hwa-Young, L. And K. Yong-Ku (2010). "Catechol-O-methyltransferase

Val158Met polymorphism affects therapeutic response to mood stabilizer in symptomatic manic patients." Psychiatry Research 175(1): 63-66. doi:10.1016/j.psychres.2008.09.011

[24] Pilar, A., M. Clemente, et al. (2005). COMT (Val158Met) polymorphism is not associated to neuropathic pain in a Spanish population. European journal of pain (London, England) 9(3): 229-232. doi:10.1016/j.ejpain.2004.06.005

[25] Katharina, D., O. Patricia, et al. (2008). "Influence of the catechol-O-methyltransferase val158met genotype on amygdala and prefrontal cortex emotional processing in panic disorder." 163(1): 13-20. doi:10.1016/j.pscychresns.2007.04.016

[26] Malhotra, A. K., L. J. Kestler, et al. (2002). "A functional polymorphism in the COMT gene and performance on a test of prefrontal cognition." Am J Psychiatry 159(4): 652-654.

[27] Awad, M. E., M. S. Abdel-Rahman, et al. (1998). "Acrylamide toxicity in isolated rat hepatocytes." Toxicol In Vitro 12(6): 699-704. doi:10.1016/S0887-2333(98)00051-4

[28] Lee, H. Y. and Y. K. Kim (2010). "CatecholO-methyltransferase Val158Met polymorphism affects therapeutic response to mood stabilizer in symptomatic manic patients." Psychiatry Res 175(1-2): 63-66. doi:10.1016/j.psychres.2008.09.011

[29] Tajouri, L., V. Martin, et al. (2006). "Genetic investigation of methylenetetrahydrofolate reductase (MTHFR) and catechol-O-methyl transferase (COMT) in multiple sclerosis." Brain Res Bull 69(3): 327-331. $\underline{10.1016 / j . b r a i n r e s b u l l .2006 .01 .005}$ 